\title{
La Naturaleza Representacional de Los Modelos ${ }^{1}$
}

José L. Falguera

Univ. de Santiago de Compostela

\section{Resumen.}

En este artículo se considera que diferentes usos del término "modelo" comparten una condición común, que viene dada por la naturaleza representacional de los modelos. Atendiendo a este punto de vista, se establece una analogía entre 'signo lingüístico' y 'modelo' que permita comprender la naturaleza representacional de los modelos. En definitiva, se asume que la teoría que permite explicar la naturaleza representacional de los modelos es la teoría del signo (Semiótica).

\section{1.- Usos de la expresión "modelo".}

En las ciencias factuales se emplea la expresión "modelo" conforme a diferentes usos. Así, siguiendo una distinción similar a la debida a M. Black (Cfr. BLACK [1962]), podemos considerar los siguientes usos:

a) Modelo como reproducción a escala de algo. Estas reproducciones a escala pueden hacerse con los mismos materiales -al menos, respecto a los aspectos fundamentales a reproducir- o con materiales diferentes de lo modelado. Este tipo de modelo puede ser a escala mayor o menor que lo modelado (y excepcionalmente es de la misma escala). Puede ser tridimensional -maquetas- o bidimensional -planos, mapas, dibujos geométricos,...-. En las ciencias factuales se emplea como instrumento descriptivo de sistemas, ya sean sistemas concretos del mundo externo o sistemas fruto de la imaginación. Lo único que hace una reproducción a escala es

${ }^{1}$ Mi agradecimiento al Prof. Harré (Univ. de Oxford), y a mis compañeros J.M. Sagüillo, J. Vazquez y L.Villegas ( estas últimos de la Universidad de Santiago de Compostela) con quienes pude dialogar de lo tratado en este trabajo. Sus comentarios han enriquecido mis puntos de vista y me han permitido evitar errores y lagunas. Debo destacar en especial la aportación del Prof. L. Villegas, ya que en diálogos con él han surgido no pocas de las ideas de este trabajo. En cualquier caso, ninguno de ellos es responsable de los errores y deficiencias que pueda encerrar este trabajo.

Éndoxa: Series Filosóficas, $n^{\circ} 3,1994$, UNED, Madrid: J.L.Falguera: La naturaleza representacional de los modelos pp. 7-29. 
plasmar aquello que ya está dado previamente, bien porque refleja un sistema concreto tal cual se nos presenta, bien porque refleja un sistema (concreto o abstracto) conforme a una descripción formulada del mismo, bien porque plasma un sistema tal cual es concebido por la imaginación. Evidentemente, estas reproducciones no pretenden incorporar todos los componentes y rasgos del asunto a reproducir; sólo aquellos que se estiman relevantes atendiendo a la función prevista para el modelo. Como ejemplos de este tipo de uso podemos señalar las estructuras metálicas que encontramos en museos de ciencia representando el sistema heliocéntrico, las estructuras de alambres y bolas representando moléculas, maquetas de presas hidráulicas, representaciones gráficas de la refracción de la luz al pasar de un medio a otro, etc. En todos estos casos la reproducción se puede emplear para descubrir o ingeniar nueva información sobre lo modelado, pero en sí misma sólo recoge la información disponible.

b) Modelo como formulación matemática de un campo de investigación. Este uso de la expresión corresponde a constructos matemáticos con los que se pretende dar cuenta y hacer posible una indagación precisa, aunque simplificada, de un determinado campo de investigación. Este uso se aplica bajo el supuesto de que cabe realizar una investigación sobre un determinado campo que, aunque simplifique los datos mediante la selección de algunos parámetros e ignorando otros que puedan ser relevantes, proporcione, a través de la formulación matemática, consecuencias interesantes y consideradas adecuadas para el conocimiento del campo. En cierta medida, las simplificaciones que introduce la formulación matemática sobre el campo de investigación quedan compensadas por el rigor que incorpora y la facilidad que supone en el manejo de los datos. Se suele hablar en este sentido de modelos matemáticos para el estudio de grupos sociales o de determinado tipo de relaciones económicas, pero también son incluibles en este tipo de uso las formulaciones matemáticas que cualesquiera disciplinas científicas utilizan para dar cuenta de diferentes parcelas del mundo externo. 
c) Modelo como analogía con respecto a determinado sistema específico. Denominado modelo analógico. En este caso no se busca la reproducción de un sistema, sino proporcionar un sistema que sea similar con el asunto del que es modelo en algún respecto. Debe resultar claro que la relación de similaridad o analogía de un sistema con respecto a otro es más débil que la de reproducción -peculiar ésta de los modelos a escala-. Al respecto señala Black que: "el modelo analógico comparte con su original no ningún conjunto de rasgos ni una proporcionalidad idéntica de magnitudes, sino, en forma más abstracta, la misma estructura o configuración de relaciones. Ahora bien, la identidad de estructura es compatible con la variación más grande de contenido, y de aquí que las posibilidades de construir modelos analógicos sean infinitas." (BLACK [1962], p. 220). Además, esta similaridad entre el modelo analógico y lo que modela no requiere disponer de facto, en cuanto entidad concreta, del sistema que es similar al asunto que se modela; es decir, en el caso de los modelos analógicos -como bien señala Achinstein-, y a diferencia de los modelos a escala, no precisan ser construidos mediante algún material, ni siquiera ser dibujados, basta describirlos mediante el lenguaje para dar cuenta de la similaridad (Cfr. ACHINSTEIN [1968], p. 211) $)^{2}$. Algunos ejemplos de este tipo de uso los encontramos en: la utilización del sistema solar como modelo analógico del átomo debida a Bohr; la utilización de las ondas formadas por la caída de una piedra en el agua como modelo analógico para la luz y el sonido por parte de Huygens; la utilización de un recipiente con bolas de billar en colisión elástica como modelo analógico para un gas. Normalmente los modelos analógicos se emplean con fines didácticos o heurísticos -incluida la utilización de formulaciones matemáticas en lo modelado que se inspiren en las ya empleadas para lo que se toma como modelo

2 En esto discrepo de Black, que parece limitar al caso de los modelos teóricos la posibilidad de presentarlos mediante mera descripción lingüística y la no necesidad de que sean construidos de facto (Cfr. BLACK [1962]). 
analógico-; pero en cuanto analógicos no son empleados para proporcionar una imagen fiel de lo modelado, ni como (re)conceptualización que proporcione una comprensión pretendidamente fidedigna de lo modelado, sino como ficción útil a los efectos didácticos o heurísticos. Claro que a partir de un modelo analógico se puede pasar a una (re)conceptualización de lo modelado de este tipo, pero eso significa la formulación de un modelo teórico acerca de lo modelado a partir de un modelo analógico. Un caso interesante de transformación de este tipo lo encontramos en la propuesta inicial de Maxwell acerca de la idea puramente geométrica de un fluido imaginario imcompresible en el que se dan las líneas de fuerza de Faraday (es decir, las líneas de fuerza de un campo eléctrico) que es concebido posteriormente por el mismo Maxwell, por Lord Kelvin y otros como un medio real con propiedades específicas -aunque llegaran a resultar paradógicas-: el éter. (Cfr. BLACK [1962], pp.223-225).

d) Modelo como (re)conceptualización de un sistema especifico, no bien conocido o comprendido. Con frecuencia este tipo de modelo es denominado modelo teórico en los análisis de Filosofía de la Ciencia. Sin duda, los modelos teóricos son los que más han interesado en Filosofia de la Ciencia. Parece que una de las características propias de un modelo teórico es que proporciona una nueva manera de concebir un sistema concreto del mundo externo, que posibilita una pretendida mejor comprensión. Esa nueva manera de concebir un sistema concreto del mundo externo se alcanza mediante aparato conceptual no disponible con anterioridad para la descripción del asunto modelado. Un modelo teórico, pues, no se propone como mera ficción acerca de lo modelado; más bien proporciona una representación conceptual del asunto modelado que se considera -o se consideró ${ }^{3}$ - adecuada. Además, un modelo teórico siempre está directamente relacionado a una teoría

3 Algo que se tomó como modelo teórico adecuado para la comprensión de determinado asunto seguirá concibiéndose como modelo teórico, aún cuando haya dejado de tomarse como adecuado. Así el modelo atómico de Bohr. 
particular, mediante la cual se pretende dar cuenta de -describir, explicar o predecir- ese ámbito del mundo al que pertenece el asunto modelado, en el sentido de que la teoría pretende dar cuenta del asunto modelado dando cuenta del modelo teórico. El ámbito del mundo sobre el que trata un modelo teórico es parcialmente describible mediante el aparato conceptual disponible con anterioridad a la creación de la teoría vinculada al modelo teórico; es decir, la conceptualización de su asunto proporcionada por el modelo teórico se pretende que complemente, mediante información proporcionada por el nuevo aparato conceptual que es específico ${ }^{4}$ de la teoría científica a la que el modelo está vinculada, la información sobre ese asunto que era disponible antes de la existencia y aplicación de esta teoría científica. Con dicho nuevo aparato conceptual se postula un diseño más completo del sistema concreto del mundo externo que constituye el asunto del modelo teórico, de manera que sea posible una mejor comprensión del sistema concreto del mundo externo en cuestión. Dicha mejor comprensión se alcanza a través de las leyes de la teoría que está en relación directa con el modelo; leyes que dan cuenta del comportamiento de ese modelo y a través de él dan cuenta del asunto que representa ese modelo. Al decir que ...se postula un diseño más completo... no estoy asumiendo que en realidad el modelo teórico proporcione el diseño completo de su asunto, ni siquiera que necesariamente proporcione algún diseño que de hecho sea más completo que otros previos. Es decir, el modelo teórico podría proporcionar un diseño como pretendidamente más completo, el cual de facto no lo fuera. En cualquier caso se emplea como dando cuenta de lo que hay, como presentando su asunto tal y como se supone que es (o se supuso que era, en el caso de que

4 Por aparato conceptual específico de una teoría $T$ se entiende aquí lo que en los análisis de la Concepción Estructuralista de Filosofía de la Ciencia se conoce como aparato conceptual T-teórico (o teórico relativamente a la teoría $\mathrm{T}$ ). El aparato conceptual disponible con anterioridad a la teoría $T$ corresponde a lo que en los análisis de la Concepción Estructuralista se conoce como aparato conceptual T-noteórico (o no-teórico relativamente a la teoría $\mathrm{T}$ ). 
el modelo haya dejado de considerarse adecuado) ${ }^{5}$. Ejemplos de este tipo de uso los encontramos en: la conceptualización de los gases como formados por partículas elásticas colisionando entre sí en relación con la teoría cinética ${ }^{6}$; la conceptualización debida a Bohr del átomo; la conceptualización corpuscular de la luz en el marco de la mecánica newtoniana; la conceptualización ondulatoria de la luz, inicialmente por Huygens y con posterioridad por Young y por Fresnel; las conceptualizaciones aristotélica, ptolemaica, copernicana, kepleriana,... del sistema cósmico; la conceptualización como estructura de doble hélice de la molécula de DNA por Crick y Watson, etc.

Tras la consideración hecha acerca de los cuatro tipos de usos de modelos de las ciencias factuales, debo indicar que, para algunos casos, estos diferentes tipos de usos mantienen relaciones interesantes entre sí: en determinados casos se pasa de un modelo analógico a un modelo teórico -en estos casos la analogía posibilita una (re)conceptualización de determinado asunto o sistema concreto que se considera relevante para su mejor comprensión-; se puede proporcionar una reproducción a escala tanto de un modelo analógico como de un modelo teórico y, aunque no es imprescindible en ningún caso, la reproducción (o modelo a escala) facilita 'la visualización' de la analogía o de la (re)conceptualización; etc.

Finalmente, parece conveniente mencionar un último tipo de uso que es propio del ámbito de la semántica formal y conforme al cual un modelo es una estructura conjuntística que se pone en relación con un lenguaje formal (o semiformal) para interpretarlo. Este uso ha sido incorporado para acometer desarrollos metamatemáticos (o metalógicos) de orientación semántica. Pero, hoy en día

5 Para una mayor consideración de los compromisos existenciales asumidos mediante modelos teóricos véase HARRÉ [1970], cap. 2.

6 Téngase en cuenta la relación del modelo teórico con el modelo analógico del recipiente con bolas de billar colisionando entre si. Comentarios similares podrían hacerse respecto de algunos de los ejemplos posteriores de modelos teóricos. 
su campo de utilización se ha ampliado a los intentos de acometer mediante técnicas formales análisis semánticos de lenguajes de sistemas lógicos y fragmentos de lenguajes naturales. En Filosofía de la Ciencia ha pasado a ocupar importante papel, al constituir un elemento clave de determinados análisis metateóricos.

\section{2.- Condición fundamental de los modelos.}

Mi pretensión hasta aquí ha sido únicamente indicar algunos de los usos más significativos de la expresión "modelo" en las ciencias factuales, proporcionando una descripción mínima de los mismos. Existen, sin duda, algunos trabajos que se interesan en plantear las distinciones entre dichos usos. Así, podemos mencionar a modo de ejemplo, ACHINSTEIN [1968], APOSTEL [1960], BLACK [1962], HARRÉ [1970], HESSE [1954] y [1963], HUTTEN [1954] ${ }^{7}$. Pero a diferencia de estos trabajos, aquí no estoy interesado en establecer las diferencias que se dan entre tales usos para plantear cómo cada tipo de uso de este ámbito contribuye a la consecución de conocimiento científico.

En cualquier caso, no quiero decir que estas distinciones carezcan de relevancia, ni que no sea importante aclarar el papel que juegan los modelos en el conocimiento científico. Sin duda tienen especial interés las consideraciones relativas a los modelos analógicos y a los teóricos, en los que se centra buena parte de la discusión acerca de la contribución de los modelos en las ciencias factuales. Pero la perspectiva que presidirá mi tratamiento de la cuestión vendrá dada por la consideración de que bajo los diferentes usos de la expresión "modelo" arriba recogidos se da una condición común que no es trivial. Cabe formular este punto de vista de manera más explícita mediante los siguientes asertos:

7 Quiero destacar el análisis proporcionado por Rom Harré en el capítulo 2 de The Principles of Scientific Thinking (HARRÉ [1970]). Ahi, Harré establece una distinción entre asunto y fuente de un modelo de cualquier tipo, para trazar una clasificación de los modelos según las relaciones que se dan entre ambos componentes de la relación de modelar. 
i) Los diferentes usos de la expresión "modelo" (que hemos considerado arriba) comparten una condición común que es fundamental a su carácter de 'ser modelo', de tal manera que subyace a dichos usos una misma noción de modelo.

ii) Cada uso (de los señalados) de la expresión "modelo" resulta de establecer condiciones específicas sobre una misma noción. ${ }^{8}$

Ante todo, procede que aclare cuál es la condición común a los diferentes usos que es fundamental a su carácter de modelo, o, dicho de otra forma, procede que caracterice la noción de modelo que propongo como común a los diferentes usos. Mi propuesta es la siguiente:

Un modelo es un sistema que postula una representación conceptual de un asunto determinado, real o ficticio, conforme a determinada finalidad. Dicha representación conceptual es un sistema abstracto.

Hay determinados aspectos en la propuesta anterior que me parece preciso aclarar a fin de que la misma sea bien entendida. Es oportuno señalar que la noción común de "modelo" a la que me

8

Hay un tipo de uso propio del ámbito de la semántica formal, conforme al cual un modelo es una estructura conjuntística que se pone en relación con un (fragmento de un) lenguaje formal (o semiformal) como interpretación que lo hace verdadero. Este uso ha sido incorporado para acometer desarrollos metamatemáticos (o metalógicos) de orientación semántica. Pero, hoy en día su campo de utilización se ha ampliado a los intentos de acometer mediante técnicas formales análisis semánticos de lenguajes de sistemas lógicos y fragmentos de lenguajes naturales. En Filosofía de la Ciencia ha pasado a ocupar importante papel, al constituir un elemento clave de determinados análisis metateóricos.

Ya P. Suppes pretendió establecer que hay una noción común a diferentes usos de la expresión "modelo" propios de las ciencias factuales y el de la semántica formal (Cfr. SUPPES [1960]). Este punto de vista ha sido cuestionado por filósofos como Black (Cfr. BLACK [1962], p. 216), Achinstein (Cfr. ACHINSTEIN [1968]. Cp. 8) y McMullin (McMULLIN [1968]). Por mi parte, creo que Suppes tiene razón, en el sentido de que el significado del término modelo es el mismo en semántica formal que en los usos para las ciencias empíricas of factuales (Crr. SUPP'ES [1960], p. 112). Esto no se debe entender como que los diferentes usos son coincidentes; por el contrario, los diferentes usos preservan sus diferencias específicas, pero comparten una condición común. Además, coincido con Suppes en que la noción de modelo de la semántica formal puede usarse como concepto central de modelo y por ello cabe emplear los modelos de la semántica formal para dar cuenta de lo que es esencial en cualquiera de los otros usos propios de la ciencias factuales: postular una representación conceptual de su asunto a modo de sistema abstracto. Pero, no intentaré justificar este punto de vista aquí, aunque sí lo he tratado en algún otro trabajo (Cfr. FALGUERA [1992]). 
refiero no es exclusiva de los usos mencionados en tanto que considerados exclusivamente en relación con contextos científicos. Debe resultar obvio que los usos de "modelo a escala" y "modelo analógico" son utilizados en contextos no científicos. Incluso se puede decir que la noción común propuesta abarca algún uso ajeno a contextos científicos, como es el de "primer ejemplar de un determinado artículo o producto, del que se pretende construir o elaborar otros, o se han elaborado otros, iguales ${ }^{1.9}$.

Pues bien, en relación con los usos aquí considerados, y conforme a la anterior propuesta, lo primero que cabe resaltar es la naturaleza representacional de los modelos. Los modelos son entidades objetivas que sirven para representar otras entidades. Pero debe resultar claro desde ahora que el papel de representación lo pueden realizar entidades que no son propiamente modelos. De esta forma, una señal de tráfico puede representar convencionalmente determinado mensaje (p.e., prohibición del paso de vehículos en determinado sentido de una calle) y no diríamos que es un modelo ${ }^{10}$. Se puede decir que el ámbito de una teoría general de la representación es más amplio que el delimitado por una teoría de los modelos y del modelizar. Me

\footnotetext{
${ }^{9}$ No obstante, encontramos otros usos de empleo cotidiano de la expresión que no parecen caer bajo la noción propuesta. Así, los de modelo como "persona que exibe atículos de moda y para la moda", o como "aquello que sirve al artista para la representación pictórica o escultórica". Cuando hablo de modelos en el resto del trabajo debe entenderse que no me estoy refiriendo a estos otros usos.

10 En lo concerniente a la delimitación entre modelos y otros tipos de entidades que se utilizan para representar, tenemos que ésta no es una cuestión del todo clara. Por ejemplo, M. W. Wartofsky parece asumir que el ámbito de los modelos cubre todo el campo de entidades que son utilizadas y utilizables en algún sentido para representar (Cfr. WARTOFSK $Y$ (1979] "Introduction"). De esta manera, llega a tomar como modelos las oraciones que pueden ser denominadas como descriptivas, por el hecho de que representan estados de cosas (Cfr. WARTOFSKY [1979], pp. 9-10). Este punto de vista puede decirse que enlaza con la concepción wittgensteiniana del lenguaje declarativo defendida en el Tractatus logico-philosophicus. Un punto de vista totalmente opuesto es el defendido por R. Harré al distinguir entre convenciones proyectivas y convenciones arbitrarias, y señalar que Wittgenstein en el Tractatus trató de asimilar las convenciones arbitrarias a las proyectivas (Cfr. HARRÉ [1970], p. 37).
} 
atrevo a pensar que ese ámbito de una teoría general de la representación es el propio de una teoría del signo. En esta línea desarrollaré en el próximo apartado algunas consideraciones sobre la naturaleza representacional de los modelos.

Cuando digo que un modelo es un sistema estoy entendiendo que un modelo es una entidad compleja con estructura, es decir, que contiene varios elementos -partes componentes-, los cuales tienen propiedades características y relaciones específicas entre sí: una totalidad organizada. Ahora bien, podría plantearse la cuestión de si un modelo es una entidad física, o una entidad abstracta o de alguna otra índole (por ejemplo, mental-subjetiva). Lo primero que cabe señalar, a fin de responder a esta cuestión, es que un modelo no es una entidad subjetiva sino que es objetiva y, por lo tanto, objeto de conocimiento intersubjetivo. Ello supone que un modelo sólo es utilizable en la medida en que está presentado mediante algún soporte material (incluyendo aquí a las expresiones -orales, escritas,...- que empleamos para describir los modelos analógicos y teóricos, así como otros procedimientos gráficos empleados en reproducciones bidimensionales). El que se presente mediante algún soporte material resulta imprescindible para asegurar su carácter intersubjetivo; pero ello no debe llevarnos a pensar que el modelo está dado sin más en el soporte material mediante el que se presenta.

Conviene recordar que en mi propuesta sobre la noción de modelo he establecido que postula una representación conceptual de su asunto atendiendo a determinada finalidad, es decir, una manera de concebir su asunto. Ello supone que la relación de modelar está asegurada por la representación conceptual específica que se postula para un determinado asunto. Esta representación conceptual -esta abstracción conceptual o conceptualización- que el modelo proporciona tiene la peculiaridad de tratar al asunto como totalidad con estructura. Es decir, en la relación de modelar 
se postula determinado sistema abstracto ${ }^{11}$ como adecuado para dar cuenta de su asunto conforme a determinada finalidad.

Atendiendo a lo dicho, ningún soporte material (ninguna entidad física) es en sí mismo modelo de nada. Lo es en tanto que tiene asociada una determinada representación conceptual. ${ }^{12}$

Tres son los componentes que hasta aquí he distinguido en la relación de modelar, a saber: soporte material, representación conceptual (sistema abstracto) y asunto. Ahora bien, el componente esencial para todos los usos de la expresión "modelo", con vistas a poder identificar que estamos ante una relación de modelar y a saber cómo entender esa relación respecto a su asunto, es la representación conceptual. De esta forma hay casos en los que podemos decir, y de hecho así se dice, que el modelo lo conforma el sistema abstracto (por ejemplo, claramente en el caso de los modelos teóricos). En estos casos el soporte material es preciso para la utilización de la representación conceptual en su relación modelizadora, pero no se establece la relación modelizadora a partir de propiedades y relaciones reconocidas como propias del soporte material en cuestión. En estos casos el soporte material expresa convencionalmente una representación conceptual (un sistema abstracto) para determinado asunto.

Se dan otros casos en los que la representación conceptual se establece a partir de propiedades y relaciones reconocidas como propias del soporte material. En estos casos la relación modelizadora depende directamente de la peculiar manera en que está

11 Entiendo "sistema" como entidad compleja con estructura, y "estructura" como la red de relaciones específicas bajo las que están organizados los elementos -partes componentes- de una entidad compleja. Aunque estrictamente no es indistinto hablar de "sistema" y de "estructura", dado que todo sistema tiene estructura y toda entidad con estructura es un sistema, pueden utilizarse ambas expresiones como si fueran sinónimas. Debe resaltarse que el sentido apuntado de las expresiones "sistema" y "estructura" es muy general y no-técnico.

12 Tal vez sea bueno aclarar que en todo momento estoy entendiendo que las entidades conceptuales ( $y$, por tanto, las representanciones conceptuales) son entidades abstractas, no entidades mentales. Además asumo que las entidades abstractas son entidades objetivas, no subjetivas. 
configurado el soporte material. Pero en estos casos no interesa el soporte material por todas las propiedades y características reconocidas como propias de éste, sino por aquellas que son distinguidas mediante una determinada representación conceptual que se proyecta sobre el correspondiente asunto. También en estos otros casos la representación conceptual (el sistema abstracto) juega el papel primordial en la relación de modelar; aunque de manera directamente dependiente del soporte material, ya que propiedades y relaciones del sistema son reconocidas como propias de dicho soporte material.

Si aceptamos lo dicho hasta aquí, no podemos establecer de maneral general ni que los modelos son entidades concretas (físicas) ni que son entidades abstractas, pero sí podemos asumir que lo esencial de un modelo es el sistema abstracto que postula, aunque en determinados casos, y atendiendo a la finalidad dada al modelo, ese sistema abstracto sea directamente dependiente del soporte material mediante el que se presenta.

Para finalizar estos comentarios aclaratorios a la propuesta dada sobre la noción de modelo parece conveniente resaltar que la finalidad prevista para un modelo determina qué va a tomarse en consideración para postular la representación conceptual (el sistema abstracto).

Si releemos ahora las descripciones proporcionadas arriba de los cuatro tipos de usos de la expresión "modelo" propios de las ciencias factuales, no debe resultar difícil constatar que mi propuesta sobre la noción de modelo es adecuada para los casos de 'modelo matemático', de 'modelo analógico' y de 'modelo teórico'. Prescindo, pues, de entrar a comentar tal adecuación. Tal vez el caso de 'modelo como reproducción a escala' exija alguna aclaración. $\mathrm{Al}$ respecto conviene resaltar que en este último caso las reproducciones no hacen otra cosa que plasmar en determinado material, configurándolo -dándole estructura-, aquellos aspectos del asunto a reproducir que son considerados relevantes atendiendo a la finalidad que se quiere dar a la reproducción. Por lo tanto, la reproducción material concreta plasma -o al menos eso se 
pretende- la abstracción conceptual que se establezca del asunto conforme al uso que se quiera hacer de la reproducción, es decir, proporciona de una manera inmediata la representación conceptual (el sistema abstracto) postulada para el correspondiente asunto. Por lo tanto, también en este caso la representación conceptual que se haga es esencial a la relación de modelar.

\section{3.- Análisis de la naturaleza representacional de los modelos.}

Conforme al anterior planteamiento es esencial a la naturaleza de ser modelo, para los usos de las ciencias factuales, el que postule un sistema abstracto para el asunto que se modela, de manera que dicho sistema abstracto constituye una representación conceptual para ese asunto. Por eso, al margen de que exista o no exista, para la relación de modelar, una dependencia directa del soporte material en que se presenta el modelo, encontramos que cada modelo puede identificarse mediante el sistema abstracto que postula.

Tenemos, pues, que el sistema abstracto que constituye la representación conceptual en la relación de modelar es el componente esencial. Sin embargo, dicho sistema abstracto no puede ser considerado aisladamente. Dicho componente debe considerarse inevitablemente en relación con los otros dos componentes ya mencionados, a saber: el soporte material en el que se presenta y el asunto modelado. Podemos decir que la relación de modelar consiste en una relación triádica entre estos tres componentes. Cabe decir que dicha relación consiste en que el soporte material expresa un sistema abstracto para representar determinado asunto.

Difícilmente puede pasar desapercibido que la relación triádica mencionada tiene una cierta semejanza con la relación triádica ya clásica propuesta para el signo. En el caso del signo se distinguen tres componentes: significante, sentido y referente. La relación triádica entre estos tres componentes del signo consiste en que el significante expresa un sentido para determinar un referente. En realidad podemos decir que la relación de modelar es un tipo de relación sígnica. 
En el campo de conocimiento de la semiótica tiene especial interés, sin duda, el caso del signo lingüístico, por ser el más analizado. Restringiéndonos a este caso tenemos que cabe considerar al signo lingüístico como una tripleta ordenada:

$$
\text { Signo Ling. }=_{d f .}<\text { Sgte., Stdo., Rfte. }>\text {. }
$$

Asumo aquí que esta relación triádica no es exclusiva del signo linguístico, sino que, como plantea U. Eco, es propia de todo proceso sígnico (Cfr. ECO [1973]). No obstante, permítaseme que de momento restrinja mis consideraciones al caso del signo lingüístico como paradigmático de la teoría de la semiótica o teoría del signo.

La relación triádica entre los tres componentes del signo lingüístico es representable gráficamente, a la manera usual, mediante una versión del triángulo semiótico de Ogden y Richards:

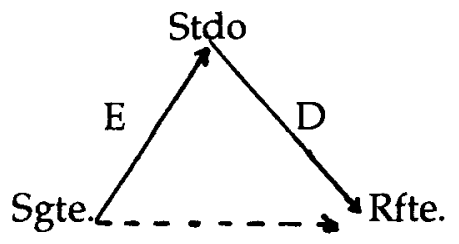

$$
\mathrm{R}=\mathrm{E} . \mathrm{D}
$$

Fig. 1

La relación triádica del signo lingüístico, tal cual es presentada en la figura 1, es descomponible en tres relaciones, dándose cada una de éstas entre cada dos componentes del triángulo semiótico de la siguiente forma:

1) Una relación $E$ de expresar, que va de los significantes a los sentidos;

2) Una relación $D$ de determinar, que va de los sentidos a los referentes;

3) Una relación $R$ de referir, que va de los significantes a los referentes. 
Tal y como muestra la figura $1, R$ es equivalente a la composición conjuntística de las relaciones $E$ y $D$, es decir,

$$
R={ }_{d f} E_{o} D \text {. }
$$

La anterior consideración del signo lingüístico toma a éste como una entidad autónoma con respecto a los usuarios del mismo. No pretendo discutir la legitimidad de este proceder; sin embargo, entiendo que el tener en cuenta la relación del signo lingǘstico con sus usuarios es pertinente en la medida en que posibilita una comprensión más completa de aquél. Al adoptar este punto de vista el análisis del signo lingüístico que propongo es algo más complejo. Acometo dicho análisis apoyándome en nociones que están inspiradas en los planteamientos de la semiótica de Ch. S. Peirce ${ }^{13}$.

Puede decirse que las nociones de significante, sentido y referente, arriba empleadas, corresponden, respectivamente y en una primera aproximación, a las de representamen, interpretante y objeto de la teoría semiótica de Peirce. Decimos "en una primera aproximación" ya que Peirce al hablar de interpretante distingue entre: interpretante inmediato, interpretante dinámico e interpretante final; y al hablar de objeto distingue entre: objeto dinámico y objeto final ${ }^{14}$. De manera similar a como Peirce descompone las nociones de interpretante y objeto, propongo descomponer en dos las nociones, que veníamos utilizando, de sentido y de referente, pasando a hablar de sentido

13 No pretendo ser fiel a los planteamientos de Peirce sobre semiótica, ni mucho menos considerar el conjunto de sus minuciosos análisis sobre el signo. Mi única pretensión es utilizar de manera sesgada algunos de los elementos de la teoría semiótica de Peirce, con el objetivo final de arrojar luz sobre la naturaleza representacional de los modelos.

14 Respecto a estas nociones y el modo en que son entendidas por Peirce pueden consultarse las siguientes obras: a) Collected Papers of Charles Sanders Peirce, recopilados por Ch. Hartshorne y P. Weiss, editados por The Belknap Press of Harvard University Press, Cambridge, Massachusetts, 1965, Vol. II, Elements of Logic, libro II, "Speculative Grammar", cap. 1, 2 y 3; b) Charles S. Peirce: Selected Writings (Values in a Universe of Chance), recopilado por Ph. P. Wiener, editado por Dover Publications, Inc., New York, 1958, cap. 24, "Letters to Lady Welby". 
inmediato y sentido dinámico, por un lado, y de referente inmediato y referente dinámico, por otro lado ${ }^{15}$.

Mediante el par sentido inmediato-sentido dinámico pretendo diferenciar los que serían los dos polos del sentido de un signo lingüístico ${ }^{16}$. El primero, sentido inmediato, tendría que ver directamente con el signo lingüístico, de manera tal que consiste en ser el concepto, o constructo conceptual, específico mediante el que el significante del signo refiere al referente, independientemente de un determinado sujeto cognoscente. Es decir, entiendo que el sentido inmediato asociado a un signo lingüístico puede considerarse con autonomía de los usuarios del signo y tiene existencia objetiva de carácter abstracto. Con ello no estoy queriendo decir que tales entidades, que constituyen el sentido inmediato de los signos, tengan existencia por sí mismas desde siempre: no son entidades platónicas; sino que una vez que un signo es constituido e incorporado por alguna comunidad de sujetos cognoscentes, se da existencia a determinado concepto o constructo conceptual específico como entidad objetiva: se trata de productos culturales. El que pueda considerarse con autonomía respecto de un determinado sujeto cognoscente no supone que tenga autonomía total respecto de la comunidad cultural en la que se utiliza ese concepto, o constructo conceptual, específico mediante determinado (o determinados) significante(s); ni tampoco el que sea una entidad objetiva conlleva el que no esté sometida a cambios y modificacio-

15 No hay correspondencia exacta entre las nociones de Peirce y las introducidas por mí, aunque sí aproximada. Así, el 'interpretante inmediato' correspondería de manera aproximada al 'sentido inmediato', el 'interpretante dinámico' al 'sentido dinámico', el 'objeto inmediato' al 'referente inmediato' y el 'objeto dinámico' al 'referente dinámico'. Prescindo, para el análisis que propongo, de la noción que le correspondería al 'interpretante final'. El 'interpretante final' de Peirce constituye la conceptualización perfecta que le correspondería al 'representamen' de un signo, en cuanto que dicho 'representamen' representa a determinado 'objeto dinámico'. Esta conceptualización perfecta es un ideal al que se tiende con el avance del conocimiento adecuado. 
nes. Su objetividad le viene de su carácter intersubjetivo, y ello mismo es lo que motiva que sea objeto de cambios. Por otro lado, algo puede ser objetivo y con identidad $y$, sin embargo, estar sometido a permanentes cambios, tal y como sucede con los seres vivos. Los sentidos inmediatos son, pues, entidades genidénticas. Los cambios que se dan en los sentidos inmediatos obedecen al desarrollo de conocimientos que tiene lugar en una comunidad cultural.

En lo que respecta al segundo polo, sentido dinámico, éste tendría que ver con el proceso cognitivo concreto que tiene lugar en cada sujeto individual cuando hace referencia a algo o representa algo: sus imágenes o/e ideas. El sentido dinámico consiste en la comprensión concreta que tiene un sujeto cognoscente en el acto de hacer referencia o representar. Se trata, pues, de algo propio de cada sujeto en cada acto de referencia o representación.

Respecto al acto de hacer referencia o representar, por parte de cada sujeto individual, cabe diferenciar los siguientes casos:

I) cuando ello supone generar un concepto, o constructo conceptual, específico totalmente nuevo;

II) cuando se hace conforme a un concepto, o constructo conceptual, específico ya existente;

III) cuando se hace modificando un concepto, o constructo conceptual, específico previamente dado.

Antes de examinar estos casos debo señalar que cuando hablo de "hacer referencia" o de "representar" no estoy tratando sobre procesos que puedan ser exclusivamente mentales y por ello subjetivos, sino que entiendo que son procesos que siempre tienen una componente objetiva, asegurada por la existencia de un concepto o constructo conceptual -esto es, un sentido inmediatoexpresable mediante algún significante. Es importante tener en cuenta esto, toda vez que entre los anteriores casos no he contemplado el que consiste en desarrollar imágenes o ideas mentales sin objetivizarlas mediante el procedimiento de comunicarlas para generar el correspondiente concepto o constructo conceptual. La razón para no considerar dicho caso no es porque afirme que no 
se da tal caso, es porque a los efectos de este trabajo no me interesan las entidades mentales en sí mismas sino en cuanto que relacionadas con el tipo de entidades abstractas a las que llamamos conceptos o constructos conceptuales.

Volviendo ahora sobre los tres casos contemplados tenemos que:

* en el caso "I)" el sentido inmediato se constituye a partir del sentido dinámico postulado, de manera que lo subjetivo y privado se transfiere -de alguna forma al conectarlo con algún significante o soporte material- en intersubjetivo y público, siendo esto último comunicable por algún sujeto a otros de su comunidad;

* en el caso "II)" el sentido dinámico se ajusta (o pretende ajustarse) al sentido inmediato correspondiente ya establecido; $y$,

* el caso "III)" se produce cuando el sujeto estima que aún siendo parcialmente útil un determinado sentido inmediato para hacer referencia o representar, no es plenamente adecuado, tal cual se concibe, en su cometido de determinar el referente o lo representado, $y$, por ello, se procede a su modificación parcial o enriquecimiento a partir del sentido inmediato.

El par referente inmediato-referente dinámico proporciona los dos polos del referente. El referente dinámico viene dado por una entidad existente o, al menos, supuestamente existente, ya sea concreta o abstracta ${ }^{17}$. El referente inmediato es el referente putativo constituido por el signo lingüístico, es decir, el referente tal cual es determinado por el sentido inmediato. Limitándonos al caso de las cosas físicas podemos decir que el referente dinámico corresponde a la cosa física como existente independientemente de todo sujeto de toda mente- y de toda conceptualización; el referente inmediato corresponde a la peculiar manera con que un concepto o constructo conceptual determina a la cosa física. Aquí se está asumiendo

17 Utilizo la expresión "entidad" en un sentido muy amplio y general que comprende desde individuos simples, a propiedades, cosas complejas,..., y que pueden ser concretos, abstractos o mentales. 
que lo existente -referente dinámico- no es determinado plenamente por aquel concepto, o constructo conceptual, específico que se le haga corresponder; es decir, el sentido inmediato determina un referente inmediato que se pretende corresponda a una entidad supuestamente existente, a un referente dinámico. No obstante, aquello que el concepto o constructo conceptual específico determina -es decir, el referente inmediato- no tiene que corresponder a algo realmente existente en el reino de entidades en que se postula que está -sea el reino de entidades concretas, o el de entidades abstractas, o el de entidades mentales-, en cuyo caso se trataría de un referente putativo que correspondería a una entidad ficticia.

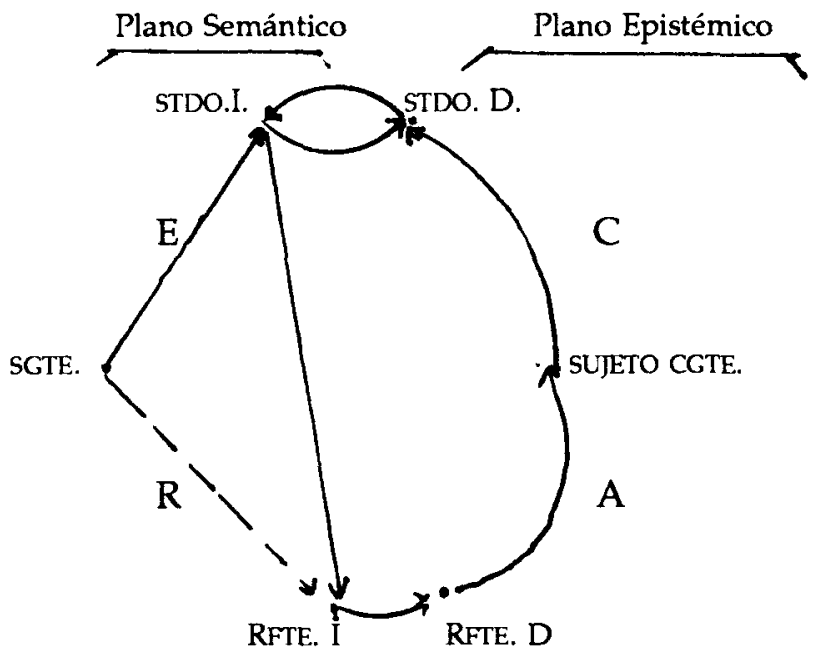
A: Es aprehendido por;
E: Expresa;
C: Concibe;
$\mathrm{R}$ : Refiere.
D: Determina;

Fig. 2

Lo dicho anteriormente puede reflejarse mediante la siguiente representación gráfica (Figura 2), que da cuenta del signo lingüístico en relación a un posible usuario:

En realidad la anterior representación gráfica (Figura 2) refleja la manera de darse la interrelación entre sujeto cognoscente y 
signo lingüístico para hacer referencia a determinada entidad. Los procesos epistémicos asociados a esta interrelación tienen asociados dos origenes diferentes:

i) Uno va de los referentes dinámicos (es decir, desde entidades existentes) a través del sujeto cognoscente para generar sentidos dinámicos (imágenes $\mathrm{e}$ ideas) mediante los que referimos a referentes inmediatos (referentes putativos) que se pretende correspondan (se adecuen) a los referentes dinámicos; en este caso se pretende reflejar la realidad ${ }^{18}$.

ii) El otro parte desde el sujeto cognoscente para generar sentidos dinámicos (imágenes e ideas) que remiten a referentes dinámicos (referentes putativos) que pueden tomarse como correspondiéndoles o meras ficciones o entidades reales; en este caso se conciben entidades posibles.

En ambos casos puede mediar el signo lingüístico, bien porque el sujeto transfiere los sentidos dinámicos que genera ex novo a sentidos inmediatos, bien porque el sujeto genera los sentidos dinámicos desde conceptos o constructos conceptuales ya existentes. De mediar el signo lingüístico se dará alguno de los casos posibles -"I)", "II)" o "III)"-, arriba mencionados, del proceso de hacer referencia.

Este largo excursus sobre el signo lingüístico puede parecer que nos ha llevado muy lejos de lo que era nuestro asunto, a saber: los modelos y su naturaleza representacional. Sin embargo, no es así. Recuérdese que había indicado que la relación de modelar es un tipo de relación sígnica. Lo que quiero plantear es que las consideraciones desarrolladas arriba sobre el signo lingüístico son aplicables a los modelos. Sólo se precisa establecer algunas correspondencias entre componentes y relaciones del signo lingüístico (o de cualquier signo), por un lado, y componentes y relaciones del modelo, por otro. Así, el soporte material de un

18 Tomo aquí la expresión de "realidad" en un sentido amplio, de manera similar a como indique que hacía con la expresión "entidad" 
modelo es su significante; este soporte material expresa un sistema abstracto; el sistema abstracto a su vez corresponde al sentido inmediato de un signo lingüístico y determina a su asunto, que corresponde al referente inmediato del signo lingüístico. En realidad al hablar de "asunto" propiamente tendría que desplegar, ahora, esta noción en dos: el "asunto proyectado" o "asunto inmediato", correspondiendo al referente inmediato; y el "asunto dinámico" correspondiendo al referente dinámico. De igual forma que el sentido inmediato determina al referente inmediato en el caso del signo lingüístico, también el sistema abstracto determina al asunto proyectado en el caso del modelo. Resulta claro que cabe decir que un sujeto cognoscente genera ideas o imágenes mentales que están relacionadas con sistemas abstractos objetivos, lo mismo que planteaba arriba para el sentido dinámico respecto del sentido inmediato. Todo ello conlleva que el análisis de un modelo es en realidad algo más complejo de lo que hasta aquí he venido asumiendo.

Ahora debe ser evidente que para dar cuenta de la naturaleza representacional de un modelo debemos tener en cuenta un gráfico similar al de la Figura 2. La representación mediante modelos es algo que realizan sujetos concretos, los usuarios de los modelos. $Y$ el acto de representación mediante un modelo puede responder a dos dinámicas:

i') la de reflejar un asunto dinámico (correspondiente al caso "i)" arriba planteado, con origen en el referente dinámico);

ii') la de concebir un asunto proyectado (o inmediato) (correspondiente al caso "ii)" arriba planteado, con origen en el sujeto cognoscente).

Obviamente estas dinámicas pueden darse de manera interna, privada, a un sujeto cognoscente, en cuyo caso se suele hablar de representación interna. Pero lo que nos interesa aqui es cuando media la relación de modelar como proceso público. Cuando media tal relación, a través de estas dinámicas - "i' ${ }^{\prime}$ " o "ii')"- se dará uno de los siguientes casos: 
$\left.I^{\prime}\right)$ la generación de un nuevo sistema abstracto como representación conceptual específica para determinado asunto (correspondiendo al caso "I)" de arriba);

II') la utilización de determinado sistema abstracto ya existente como representación conceptual específica para determinado asunto proyectado (correspondiendo al caso "II)" de arriba);

III') la utilización de determinado sistema abstracto ya existente, que es modificado parcialmente o enriquecido, como representación conceptual específica de determinado asunto proyectado (correspondiendo al caso "III)" de arriba).

De lo hasta aquí dicho se desprende que la relación de modelar está estrechamente relacionada con los procesos cognitivos; es más, constituye un medio fundamental en la adquisición y establecimiento de conocimiento, tanto a nivel personal como intersubjetivo. El conocimiento es representación y, aunque la actividad mental es imprescindible para que haya conocimiento, no se obtiene conocimiento con la mera representación interna (mental), es preciso que haya representación externa expresada mediante algún soporte material, mediante algún significante ${ }^{19}$.

\section{REFERENCIAS BIBLIOGRAFICAS}

ACHINSTEIN, P.[1968] Concepts of Science. A Philosophical Analysis. The Johns Hopkins Press. Baltimore and London.

APOSTEL, L.[1960] "Towards the Formal Study of Models in the Non-formal Sciences", en: Synthese, 12: 125-161.

BLACK, M. [1962] "Models and Archetypes", en: BLACK, M. Models and Metaphors, Conell Univ. Press, New York-1962 (Vers. Cast.: "Modelos y Arquetipos", en: BLACK, M. Modelos y Metáforas, Ed. Tecnos, Madrid-1966).

19 Wartofsky es más rotundo al respecto: "... I would argue that such 'mental' objects, or 'internal representations' are derivative, and have their genesis in our primity activity of representing, in wich we take external things, -most tipically, what we also designate as physical objects- as representations. Moreover, I take our making of representations to be, in the first place, the actual praxis of creating concrete objects-in-the-world, as representations; or of taking the made objects as representational." (WARTOFSKY [1979], pp. xxi-xxii) 
ECO, U.[1973] $l$ Signo. Istituto Edit. Internazionales, Milán. (Vers. Cast.: Signo. Ed. Labor, Barcelona-1980)

FALGUERA, J.L.[1992] "La Noción de Modelo en los Análisis de la Concepción Estructuralista", en: Agore, 11/1: 97-104.

IDEM: [1993] "Notional Unity Underlying the Use of the Term 'Model' in Mathematical and Empirical Science", (to be published).

HARRE, R.[1970] The Principles of Scientific Thinking. MacMillan, London.

HESSE, M.[1954] "Models in Physics", en: The British Journal for the Philosophy of Science, 4: 198-214.

IDEM: [1963] Models and Analogies in Science. Sheed and Ward Ltd., London.

HUTTEN, E.H.[1954] 'The Role of Models in Physics", en: The British Journal for the Philosophy of Science, 4: 284-301.

McMULLIN,E. [1968] "What Do Physical Models Tell Us?", en: B. Van ROOTSELAAR y J.F. STAAL (Eds.) Logic, Methodology and Philosophy of Science III, pp. 385396. North Holland. Amsterdam.

SUPPES, P. [1960] "A Comparison of the Meaning and Uses of Models in Mathematics and the Empirical Sciences", en: Synthese, 12, 287-301.

WARTOFSKY, M.W. [1979] Models: Representation and the Scientific Understanding. Reidel, Dordrecht. 